\title{
CALIDAD DEMOCRÁTICA, SISTEMA INSTITUCIONAL Y MODELO TERRITORIAL VASCO
}

\author{
SANTIAGO LARRAZABAL BASAÑEZ
}


SUMARIO

1. INTRODUCCIÓN. 2. LA DISTRIBUCIÓN DE COMPETENCIAS ENTRE LAS INSTITUCIONES COMUNES DE LA COMUNIDAD AUTÓNOMA DE EUSKADI Y LOS ÓRGANOS FORALES DE LOS TERRITORIOS HISTÓRICOS DE BIZKAIA, GIPUZKOA Y ÁLAVA. 2.1. LA DISTRIBUCIÓN DE COMPETENCIAS EN EL ESTATUTO DE AUTONOMÍA DEL PAÍS VASCO. 2.2. LA DISTRIBUCIÓN DE COMPETENCIAS EN LA LEY DE TERRITORIOS HISTÓRICOS. 3. LAS COMPETENCIAS DE LAS INSTITUCIONES LOCALES DE EUSKADI. 4. CONCLUSIÓN. 


\title{
CALIDAD DEMOCRÁTICA, SISTEMA INSTITUCIONAL Y MODELO TERRITORIAL VASCO
}

\author{
SANTIAGO LARRAZABAL BASAÑEZ
}

\section{INTRODUCCIÓN}

En el ámbito académico se ha suscitado un profundo a la par que sugerente debate acerca de si los sistemas territorialmente descentralizados, con sus virtudes y defectos, suelen dar mejores resultados que los que no lo son en ámbitos clave como, por ejemplo, organización administrativa, calidad del sistema de gobernanza, resultados económicos ${ }^{2}$, desarrollo humano, participación ciudadana, transparencia del sistema y en definitiva, en aquellos aspectos que pueden mejorar la calidad democrática de las sociedades a las que sirven. Y no son pocos los autores que defienden que $s^{3}$.

${ }^{1}$ Profesor de Derecho Constitucional. Facultad de Derecho. Universidad de Deusto. Avda. de las Universidades, 24. 48007 Bilbao. E-mail: santiago.larrazabal@deusto.es

${ }^{2}$ Como dejó dicho y de una forma muy gráfica además, Juan Luis LASKURAIN, «... prácticamente no hay ningún país en el mundo, desde luego, no se me ocurre ahora ninguno, de estructura descentralizada, federal, que esté en la miseria». Juan Luis LASKURAIN ARGARATE conoce muy bien el sistema institucional vasco y el modelo de Concierto Económico. Participó como Director de Estudios en el equipo de Pedro Luis URIARTE SANTAMARINA, que fue el Consejero de Hacienda del Gobierno Vasco que negoció la recuperación del Concierto Económico Vasco en 1981. LASKURAIN fue asesor técnico de la delegación negociadora vasca, Diputado de Hacienda de la Diputación Foral de Bizkaia y Presidente del Tribunal Vasco de Cuentas. El texto, aparece en ALCEDO MONEO, M. (2007), La identidad pactada. Primer proceso estatutario y Concierto Económico de 1981, Bilbao, AD CONCORDIAM, pág. 163.

${ }^{3}$ Sobre este particular, pueden consultarse, por ejemplo: BLAS MENDOZA, A. (2012), «Modelos de democracia en las Comunidades Autónomas españolas», Zaragoza, Fundación Manuel Giménez Abad; CALRE (2013). Grupo de Trabajo «Modelos regionales institucionales-democracia regional. Informe y conclusiones». Asamblea Plenaria CALRE, Bruselas, 21-22 de octubre de 2013 http://www. parlamentodegalicia.es/sitios/web/BibliotecaDocumentosVarios/2013-10-INFORME-CONCLUSIONES_ ES.pdf (última consulta, 10 de septiembre de 2017); CASTEL GAYÁN, S. (2011), «Descentralización política, participación ciudadana y renovación jurídica: ‘hacia una democracia participativa?, Revista catalana de Dret Public, núm. 43, págs. 279-316; CASTEL GAYÁN, S. (2013), «Gobierno abierto en el Estado autonómico: régimen jurídico y estrategias», Revista aragonesa de Administración Pública, número extra 14, 
Yo también comparto esas ideas y, por tanto, mi hipótesis de trabajo abunda en este mismo sentido. En mi opinión, al igual que ocurre en otros modelos de distribución territorial del poder tanto en el derecho comparado como en el derecho español, el sistema institucional y territorial vasco vendría a confirmar esa misma idea. Pero para ello, resulta obligado en primer lugar explicar en qué consiste y cómo se organiza el modelo institucional y territorial vasco, sobre todo para aquellos lectores que no estén familiarizados con él. Una vez explicado éste, intentaré demostrar que a pesar de su complejidad, el modelo vasco es otro ejemplo más que viene a corroborar la idea ya apuntada anteriormente de que un modelo territorialmente descentralizado favorece la calidad democrática y el desarrollo económico y social. Para ello, aportaré algunos datos objetivos y mensurables que lo confirman, datos a los que me referiré al final de este trabajo, para poder justificar laconclusión final del mismo.

págs. 159-201; CHARRON, N./ LAPUENTE, V./ DIJKSTRA, L. (2012), Regional Governance Matters: a Study on the Regional Variation in Quality Government within the EU. Working Paper 01/2012, European Commision, Directorate General for Regional Policy, http://ec.europa.eu/regional_policy/sources/docgener/ work/2012_02_governance.pdf (última consulta, 10 de septiembre de 2017); CHARRON, N. / LAPUENTE, V. (2013), «Why do some Regions in Europe have a higher quality of government?», Journal of Politics, núm. 7, vol. 75-3, págs. 567-582; CHARRON, N./ LAPUENTE, V./ DIJKSTRA, L. (2014), «»Regional Government matters: Quality of Government within European Union Member States», Regional Studies, núm. 48, págs. 68-90. http://dx.doi.org/10.1080/00343404.2013.770141; COLINO, C. / DEL PINO, E. (2011), «Spain: the consolidation of strong Regional Government and the limits of local descentralization», en LOUGHLIN, J./ HENDRIKS, F./ LINDSTRÖM, A. (eds.), The Oxford Handbook of Local and Regional Democracy in Europe, Oxford, Oxford University Press, págs. 356-383; COLINO, C. (2013), «El debate sobre la calidad democrática: calidad democrática, crisis y reformas en el Estado autonómico», Informe Comunidades Autónomas 2013, Barcelona, Instituto de Derecho Público, págs. 37-69; COLINO, C., «Calidad democrática, crisis y reformas en el Estado autonómico» en https://www.foroautonomias.es/wp-content/uploads/2014/05/ calidad_democratica.pdf (última consulta, 10 de septiembre de 2017); COLINO, C./ HOMBRADO, A. (2015), «Territorial Pluralism in Spain: characteristics and assessment» en BASTA, K.. / Mc GARRY. J. I SIMEON, R. (eds.), Assessing Territorial Pluralism, Vancouver, Universtiy of Brtitish Columbia, págs. 171195; DEL REAL ALCALÁ, J.A. (2013), «Informe Calidad-Democrática, descentralización y Constitución española», Cuadernos Manuel Jiménez Abad, 6 (diciembre de 2013), págs. 181-206; NISTOTSKAYA, M. I CHARRON, N. / LAPUENTE, V. (2015), The wealth of regions: quality of government and SME in 172 European Regions», Environment and Planning C: Government and Policy, vol. 33-5, págs. 1125-1155; PASCUAL ESTEVE, J.M. ${ }^{2} /$ GOLDÁS i PÉREZ, D. (2010), «El buen gobierno 2.0. La Gobernanza democrática territorial: ciudades y regiones por la cohesión social y una democracia de calidad», Valencia, Tirant Lo Blanch; PEDRAJA CHAPARRO, A. /SUÁREZ PANDIELLO, J. (2015), «La arquitectura del sistema descentralizado en España: Comunidades Autónomas y Corporaciones Locales», Papeles de Economía española, núm.143, págs. 1-27; RODRÍGUEZ HERRERO, G. (2010), Los modelos de descentralización y participación ciudadana en el punto de mira: escenarios plurales y resultados complejos, Vitoria-Gasteiz, Servicio Central de Publicaciones del Gobierno Vasco; RODRÍGUEZPOSE, A. (2013), «Do Institutions matter for regional development?», Regional Studies, núm. 47, págs. 1034-1047; RUIZ-RICO, C./ CASTEL GAYÁN, S. (2013), «El derecho autonómico de participación ciudadana: un enfoque constitucional y su desarrollo legislativo", Revista de Estudios Jurídicos de la Universidad de Jaén, núm.13, págs. 1-33; RUIZ -RICO RUIZ, C. (2014), Transparencia en el Estado Autonómico, Madrid, Dykinson, págs. 20-29; TUDELA ARANDA, J./ KÖLLING, M./ REVIRIEGO PICÓN, F. (2018), Calidad democrática y organización territorial, Madrid, Marcial Pons; TUSELL COLLADO, A. (2015), «La calidad de la democracia y sus factores determinantes», Politica y Sociedad, vol. 52-1, págs. 179-204; 
La Comunidad Autónoma de Euskadi tiene un sistema de organización interna tripartito en el que la distribución territorial del poder se estructura en un complejo modelo institucional que integra tres niveles distintos: el de las Instituciones Comunes de la Comunidad Autónoma (esto es, el Parlamento Vasco —órgano legislativoy el Gobierno Vasco —órgano ejecutivo-), el de los Órganos Forales de cada uno de los tres Territorios Históricos que actualmente la componen: Bizkaia, Gipuzkoa y Álava (es decir, las tres Juntas Generales, una por cada Territorio, _órganos asamblearios-y las tres Diputaciones Forales, una por cada Territorio —órganos ejecutivos-) y el correspondiente a los Municipios y demás Instituciones Locales. Cada una de estas instituciones tiene legitimidad democrática plena y todas ellas comparten un sistema de gobierno parlamentario, pues tanto el Parlamento Vasco (Parlamento autonómico), como las Juntas Generales (Parlamentos provinciales de cada uno de los tres Territorios Históricos) son Asambleas elegidas directamente por el Pueblo, y evidentemente, la legitimidad democrática plena es también predicable de los Municipios, cuyos concejales son también directamente elegidos por el Pueblo. De este modo, sus respectivos órganos asamblearios eligen a su vez a la cabeza de cada uno de sus órganos ejecutivos (Lehendakari, tres Diputados Generales — uno por cada Territorio Histórico- y 251 Alcaldes $)^{4}$.

${ }^{4}$ Existe una amplísima bibliografía sobre el entramado institucional vasco que no es posible consignar íntegra en este trabajo. Por citar algunas de las obras más relevantes al respecto y sin ánimo de exhaustividad, destacaría las siguientes: ARLUCEA RUIZ, E. (2000), Los Territorios históricos de la Comunidad Autónoma Vasca, Bilbao, Fundación Elkargunea; ARRIETA ALBERDI, J. (2001), «Las imágenes de los Derechos Históricos: un estado de la cuestión», en HERRERO Y RODRÍGUEZ DE MIÑÓN, M. / LLUCH MARTÍN, E., Derechos históricos y constitucionalismo útil, Madrid, 2011, págs. 221-274; CAÑO MORENO, J. (2007), Derecho Autonómico Vasco, Bilbao, Universidad de Deusto; CASTELLS ARTECHE, J.M., coord. (1991), Estudios sobre el Estatuto de Autonomía del País Vasco, Oñati, Instituto Vasco de Administración Pública; CELAYA IBARRA, A. / CELAYA URIBARRI, A.(1992), Derecho Autonómico Vasco, Bilbao, Universidad de Deusto; CLAVERO, B. (1985), Fueros Vascos. Historia en tiempos de Constitución, Barcelona, Ariel; COELLO MARTÍN, C. (1997), La Disposición Adicional Primera y la organización autonómica vasca, Logroño, Publicaciones de la Universidad de La Rioja; CORCUERA ATIENZA, J.(1991), Política y Derecho: la construcción de la autonomía vasca, Madrid, Centro de Estudios Constitucionales; CORCUERA ATIENZA, J. / GARCÍA HERRERA, M.A. (2002), La constitucionalización de los Derechos Históricos, Madrid, Centro de Estudios Políticos y Constitucionales; FERNÁNDEZ RODRÍGUEZ, T.R. (1985), Los Derechos Históricos de los Territorios Forales, Madrid, Civitas /Centro de Estudios Constitucionales; FERNÁNDEZ SEGADO, F. (1999), «Disposición Adicional Primera. Los Derechos Históricos de los Territorios Forales» en ALZAGA VILLAAMIL, O. (dir.), Comentarios a la Constitución Española de 1978, Madrid, EDERSA; GARCÍA PELAYO, M. (1991), «El proyecto constitucional y los Derechos Históricos» en Obras Completas, Madrid, Centro de Estudios Constitucionales, vol. III, págs. 3171-3177; GONZÁLEZ DE ZÁRATE LORENTE, R. (2017), El ordenamiento político-administrativo de los Territorios Forales de Euskadi, Oñati, Instituto Vasco de Administración Pública; HERRERO DE MIÑÓN, M. (1991), Idea de los Derechos Históricos, Madrid, Ed. Espasa-Calpe; HERRERO DE MIÑON, M. (1998), Derechos Históricos y Constitución, Barcelona, Editorial Taurus; HERRERO DE MIÑÓN, M./ LLUCH, E.(eds.) (1998), Foralismo, derechos históricos y democracia, Bilbao, Fundación BBV; HERRERO DE MIÑÓN, M./ LLUCH, E. (eds.) (2000), Derechos históricos y constitucionalismo útil, Bilbao, Fundación BBV; JIMÉNEZ ASENSIO, R. (1997), «El sistema de fuentes del derecho de la Comunidad Autónoma del País Vasco 
Cada nivel institucional tiene además sus propias competencias, en algunos casos muy notables, y una financiación específica, derivada del régimen de Concierto Económico que, como es sabido, constituye uno de los derechos históricos de los Territorios Forales amparados por la Disposición Adicional Primera de la Constitución y cuya actualización se ha producido y se sigue produciendo en el marco constitucional y estatutario.

Todos estos elementos hacen del sistema de organización interna de la Comunidad Autónoma de Euskadi un modelo particular y ciertamente complejo, que aúna elementos federales con elementos de inspiración confederal ${ }^{5}$. De hecho, en una Comunidad con algo menos de dos millones doscientos mil habitantes, tenemos cuatro Gobiernos (el Gobierno Vasco y las tres Diputaciones Forales), cuatro Asambleas (el Parlamento Vasco y las tres Juntas Generales) y 251 municipios. Dicho así, sin matizar, puede parecer una "pequeña locura», pero como decía Aristóteles, no hace falta un gobierno perfecto, lo que se necesita es uno que sea práctico y que fun-

como ordenamiento asimétrico», Revista Vasca de Administración Pública, núm., 47, págs. 127-172; LAPORTA, F.J. / SAIZ ARNAIZ, A (2006), Los Derechos Históricos en la Constitución, Madrid, Centro de Estudios Políticos y Constitucionales; LAMARCA ITURBE, I. (1992), Derecho Autonómico Vasco, Donostia-San Sebastián, Ed. Librería Carmelo; LAPORTA SAN MIGUEL, F.J. / SAIZ ARNÁIZ, A. (2006), «Los derechos históricos en la Constitución: algunos problemas técnicos», en VV. Los derechos históricos en la Constitución, Madrid, Centro de Estudios Políticos y Constitucionales, págs. 9-86; LARRAZABAL BASAÑEZ, S. (1997), Contribución a una Teoría de los Derechos Históricos Vascos, Oñati, Instituto Vasco de Administración Pública; LASAGABASTER HERRARTE, I. (2007), Derecho Público en Euskal Herria, Bilbao, Ed. Lete; LEGUINA VILLA, J. (1981), «Los Territorios Históricos Vascos. Poderes normativos y conflictos de competencia», Revista Española de Derecho Constitucional, núm. 3; LOJENDIO IRURE, I.M. (1988), La Disposición Adicional Primera de la Constitución Española, Oñati, Instituto Vasco de Administración Pública; MARTÍNEZ ETXEBERRIA, G., (2017), Los Territorios Históricos Vascos y su producción normativa foral: unas realidades fronterizas en busca del mejor encaje en el sistema, Bilbao, AD CONCORDIAM: MUÑOZ MACHADO, S. (1992), «La Disposición Adicional Primera de la Constitución» en MARTÍN RETORTILLO, S. (dir.), Derecho Público Foral de Navarra. El Amejoramiento del Fuero, Gobierno de Navarra/ Civitas, págs. 223-244; PORRES AZKONA, J. (1992), Política y Derecho. Los Derechos Históricos Vascos, Oñati, Instituto Vasco de Administración Pública; RAZQUIN LIZARRAGA, M.M., «Organización Foral y hecho diferencial», en COELLO MARTÍN, C. (2000), El Estado Autonómico y Hecho diferencial de Vasconia, Eusko Ikaskuntza / Sociedad de Estudios Vascos, Donostia-San Sebastián; SOLOZABAL ECHEVARRIA, J.J. (2000), «Derechos Históricos, Constitución y Soberanía», Claves de la Razón Práctica, núm. 107, págs. 11 y ss; TAMAYO SALABERRIA, V. y C. (1981), Fuentes documentales y normativas del Estatuto de Gernika, Vitoria-Gasteiz, Diputación Foral de Álava; TUDELA ARANDA, J., «Comentarios a la Disposición Adicional Primera de la Constitución», en CASAS BAAMONDE, M.E. / RODRÍGUEZ-PIÑERO y BRAVO-FERRER, M., Comentarios a la Constitución Española, Madrid, Wolter Kluwers, págs. 2776-2787; VV.AA. (1983), Primeras Jornadas de Estudio del Estatuto de Autonomía del País Vasco, Oñati, Instituto Vasco de Administración Pública; VV.AA. (1986), Jornadas de Estudio sobre la actualización de los Derechos Históricos Vascos, Bilbao, Servicio Editorial de la Universidad del País Vasco; VV.AA. (1988), II Congreso Mundial Vasco: Los Derechos Históricos Vascos, Oñati, Instituto Vasco de Administración Pública; VV.AA. (1991), Cuestiones particulares del Régimen Foral y Local Vasco, Oñati, Instituto Vasco de Administración Pública.

${ }^{5}$ NOVO ARBONA, A. (2010), La excepcionalidad del modelo federal foral vasco, Valencia, Tirant lo Blanch. 
cione, y dicho sea con toda modestia, a pesar de todo, y aunque el sistema vasco es bastante mejorable, en la práctica... funciona... aceptablemente ${ }^{6}$.

En efecto, el modelo vasco de vertebración territorial interna es complejo porque tiene que servir a una sociedad como la vasca, eminentemente compleja y plural y es que, como he escrito en otro lugar, «la complejidad forma parte integrante de nuestro ADN político, económico, lingüístico, territorial, social, e incluso deportivo y, como no podía ser menos, también jurídico» ${ }^{7}$. Y, por tanto, es el sistema jurídico el que debe adaptarse a la realidad que pretende regular y no al contrario, como a veces, en un alarde de estéril arrogancia, pretendemos los juristas. En otras palabras, un País tan complejo como el País Vasco no funcionaría adecuadamente sin un modelo territorial tan descentralizado como el vasco y aunque ese modelo territorial descentralizado complica a veces bastante las cosas, tiene también efectos positivos, entre ellos, promover una mayor calidad democrática, como intentaré demostrar a lo largo de este trabajo.

Ello no supone que los actuales sistema institucional y modelo territorial vascos sean en su diseño mejor o peor que otros, pero creo que, en el contexto actual, son los más factibles. Parafraseando el refrán castellano, «con estos mimbres no se puede hacer más que este cesto», al menos de momento, y el «cesto» — si se me permite la expresión - es complejo, caro, provoca inevitables duplicidades y solapamientos, pero y en lo que se refiere al objeto de este trabajo, que versa sobre calidad democrática, exige para funcionar — ya que de lo contrario, el sistema se bloquea - el acuerdo entre instituciones territoriales diferentes (autonómicas, forales y locales), que tienen intereses distintos (incluso aunque pertenezcan al mismo partido político), que a menudo están gobernadas por fuerzas políticas diferentes, frecuentemente no bien avenidas entre sí e incluso antagónicas, y que salvo en rarísimas excepciones no tienen mayoría absoluta, lo que hace que el poder esté mucho más repartido, que los partidos y las instituciones se controlen entre sí y que haya que aprender a cooperar entre partidos e instituciones, puesto que se requiere el acuerdo entre diferentes para que los temas

${ }^{6}$ A este respecto, puede consultarse el Informe sobre el análisis y funcionamiento institucional en la Comunidad Autónoma de Euskadi que durante la X Legislatura del Parlamento Vasco (2012-2016) elaboró el Gobierno Vasco, integrado por el Partido Nacionalista Vasco en minoría y que remitió al Parlamento Vasco, en particular, sus págs. 1-87.

https://www.irekia.euskadi.eus/uploads/attachments/4109/INFORME_SOBRE_ANALISIS_Y_ FUNCIONAMIENTO_INSTITUCIONAL_EN_EUSKADI_CAST_04-02-2014.pdf?1391510247

(Última consulta, 10 de septiembre de 2017).

Sin embargo, elInforme sobre Duplicidades e Ineficiencias en las Administraciones Públicas Vascas, de septiembre de 2011, elaborado en la IX Legislatura, cuando el PSE-PSOE estaba al frente del Gobierno Vasco, era mucho más crítico con el inevitable problema de las «duplicidades»en un marco institucional tan complejo como el vasco. Puede consultarse en:

http://www.irekia.euskadi.eus/uploads/attachments/2540/Informe_duplicidades_e_ineficiencias_en_las_Administraciones_Publicas_Vascas_informe_completo_.pdf?1347621872 (Última consulta, 14 de febrero de 2018).

7 LARRAZABAL BASAÑEZ, S. (2017), «Zume hauekin...ekin lanari. Reflexiones sobre la génesis, naturaleza e inserción de la Ley de Instituciones Locales de Euskadi en el peculiar sistema de fuentes del Derecho vasco», Revista Vasca de Administración Pública, núm.107-II, pág. 21. 
salgan adelante, lo que no es en modo alguno sencillo, pues ninguna de ellas tiene poderes de coordinación decisivos sobre las demás.

En consecuencia, todo ello supone un mayor control de las instituciones por distintos elementos políticos y por tanto, un refuerzo de la participación política y de la pluralidad, y en definitiva, de la calidad democrática del sistema, aunque el precio a pagar sea el de una gobernabilidad compleja ${ }^{8}$. Así las cosas, el sistema obliga a los

${ }^{8}$ La complejidad del modelo político-institucional vasco puede verse claramente reflejada en la composición de los distintos órganos de gobierno de los tres niveles institucionales vascos y en los difíciles equilibrios que hay hacer para garantizar la gobernabilidad de todas las instituciones. A pesar de que el Partido Nacionalista Vasco (EAJ-PNV) es el partido predominante en gran parte de las instituciones políticas vascas, y podría parecer a simple vista que éste es el elemento determinante para que el sistema funcione aceptablemente, las cosas no son tan sencillas: de hecho, el PNV no ha gozado casi nunca de mayoría absoluta en las instituciones, de tal manera que donde ha gobernado, lo ha hecho casi siempre a través de gobiernos de coalición, pactos de legislatura o directamente en minoría, lo que le ha obligado a pactar con otras fuerzas políticas y a intentar afrontar a veces con más éxito y otras con menos, tensiones entre fuerzas políticas y sociales y tensiones territoriales entre las Instituciones Centrales vascas y las de sus Territorios Históricos. Piénsese que incluso en el propio seno del PNV se han producido este tipo de tensiones, que incluso le supusieron una dolorosa escisión: el 2 de marzo de 1985 dimitió el entonces Lehendakari por el PNV Carlos Garaikoetxea y en 1986, se produjo una escisión dentro del PNV, con el nacimiento de un nuevo partido con el nombre de «Eusko Alkartasuna» (EA), encabezado por el ya ex- Lehendakari Garaikoetxea, escisión que se mantiene aún hoy.

Por aportar algunos datos concretos sobre la compleja gobernabilidad de las instituciones políticas vascas, habría que hacer notar que, en el ámbito de las Instituciones Comunes de la Comunidad Autónoma del País Vasco, en el Parlamento Vasco, si bien el PNV ha sido casi siempre la fuerza más numerosa en votos y escaños (salvo en la III legislatura, 1987-1991, en que lo fue el PSE-PSOE en escaños pero no en votos), nunca ha tenido mayoría absoluta en él. Dada la composición del Parlamento Vasco, su corolario, en un sistema de gobierno parlamentario como el vasco, ha sido que en el Gobierno Vasco ha habido de todo: gobiernos monocolores en minoría del PNV en las legislaturas I (1980-1984), II (1984-1985) y X (20012-2016); de coalición con el PSE-PSOE en las legislaturas III (1987-1991), IV (1991-1995) y en la actual, la XI (desde 2016 hasta hoy); de coalición con Eusko Alkartasuna (EA) que, como acabamos de ver, es un partido nacido de la escisión del propio PNV, en las legislaturas IV (1991) y VI (1999-2001); de coalición con PSE-PSOE y EA en la V Legislatura (1995-1999); de coalición con EA y EB(Ezker Batua /Berdeak) en la VII Legislatura (2001-2005) y en la VIII (2005-2009). En la IX Legislatura (2009-2012), fue el PSE-PSOE con el apoyo parlamentario del PP quien encabezó el Gobierno Vasco, a pesar de que el partido mayoritario en votos y en escaños en el Parlamento Vasco fue el PNV.

En el ámbito de los Territorios Históricos, y en concreto si nos fijamos en lasDiputaciones Forales, en Bizkaia, el PNV ha encabezado siempre la Diputación Foral, pero ha alternado épocas con gobiernos monocolores, generalmente en minoría, con otras con gobiernos de coalición con PSE-PSOE y con EA. En Álava, el PNV ha liderado la Diputación Foral durante las legislaturas I (1979-1983), II (19831987), IV (1991-1995), V (1995-1999), VIII (2007-2011) y en la actual X Legislatura (2015 hasta hoy), bien en minoría o en coalición con PSE-PSOE y con EA; el PSE-PSOE gobernó la Diputación Foral en la III Legislatura (1987-1991) en coalición con el PNV y el PP ha gobernado la Diputación Foral en las legislaturas VI (1999-2003), VII (2003-2007) y IX (2011-2015) aunque sin tener tampoco mayoría absoluta. En Gipuzkoa, el PNV ha liderado la Diputación Foraldurante las legislaturas I (1979-1983), II (1983-1987), IV (1991-1995), V (1995-1999), VI (1999-2003), VII (2003-2007); VIII (2007-2011) y la actual, esto es, la X (de 2015 en adelante), pero o bien en minoría o bien en coalición con el PSEPSOE y con EA; por su parte, EA la lideró en la III Legislatura (1987-1991) y EH-Bildu (Euskal-Herria Bildu) en la IX (2011-2015). 
diferentes actores políticos e institucionales a «pactar», a llegar a acuerdos (a veces aunque sea «a regañadientes») si quieren que el sistema funcione y obviamente, a todos les interesa que funcione. $\mathrm{Y}$ de hecho, con sus virtudes y defectos, considero que funciona aceptablemente aunque, como todo en la vida, es mejorable.

\section{LA DISTRIBUCIÓN DE COMPETENCIAS ENTRE LAS INSTITUCIONES COMUNES DE LA COMUNIDAD AUTÓNOMA DE EUSKADI Y LOS ÓRGANOS FORALES DE LOS TERRITORIOS HISTÓRICOS DE BIZKAIA, GIPUZKOA Y ÁLAVA}

\subsection{La distribución de competencias en el Estatuto de Autonomía del País Vasco}

Como ya tuve ocasión de explicar en un trabajo anterior sobre este tema ${ }^{9}$, para comprender cómo funciona la distribución interna de competencias entre las Instituciones Comunes del País Vasco (Gobierno y Parlamento Vascos) y las de los Órganos Forales de sus Territorios Históricos (Juntas Generales y Diputaciones Forales de Bizkaia, Gipuzkoa y Álava), debemos recurrir en primer lugar al Estatuto de Autonomía de Gernika de $1979^{10}$. En el modelo de vertebración interna del País diseñado en el mismo, además de las Instituciones Comunes de la Comunidad Autónoma, los Territorios Históricos de Bizkaia, Gipuzkoa y Álava se configuran como poderes del País Vasco, que tienen reservadas una serie de competencias que constituyen un núcleo intocable para el legislador autonómico vasco. Entre estas competencias deben mencionarse las incluidas en los artículos 3 (competencias para conservar, restablecer y actualizar su organización e instituciones privativas de autogobierno), 10.34 (carreteras y caminos), 24.2 (conservación y organización de

En el ámbito municipal, si nos referimos a las tres capitales vascas, por poner algunos ejemplos, durante la democracia, el PNV ha gobernado siempre en Bilbao, pero en minoría o en coalición con el PSE-PSOE, EA, Ezker Batua e incluso brevemente con el PP, y sólo una vez, durante el período 20112015 tuvo mayoría absoluta. En Vitoria-Gasteiz ha habido alcaldes del PNV, EA, PSE-PSOE y PP, bien en solitario en minoría o en coalición. Y en Donostia-San Sebastián, ha habido alcaldes del PNV, EA, PSE-PSOE y EH-Bildu, también en solitario o en coalición.

9 LARRAZABAL BASAÑEZ, S. (2010), « ¿26 años no es nada...? Luces y sombras en la distribución de competencias entre las Instituciones Comunes de la Comunidad Autónoma del País Vasco y la de sus Territorios Históricos», Revista Vasca de Administración Pública, núms. 87-88, págs. 707-718. A este respecto, puede consultarse también: LÓPEZ BASAGUREN, A. (2006), «Informe sobre la distribución de competencias entre las Instituciones Comunes de la Comunidad Autónoma del País Vasco y sus Territorios Históricos» en GARCÍA CRESPO, M. (dir.), Evaluación y cuantificación de la distribución competencial existente entre el Gobierno Vasco y los tres Territorios Históricos, con especial referencia al Territorio Histórico de Álava, Departamento de Economía Aplicada V, Bilbao, Universidad del País Vasco, págs. 38 y ss.

${ }^{10}$ Ley Orgánica 3/1979, de 18 de diciembre, de Estatuto de Autonomía para el País Vasco (publicada en el Boletín Oficial del Estado de 22 de diciembre de 1979, n. ${ }^{\circ} 306$ y en el Boletín Oficial del Consejo General del País Vasco, de 12 de enero de 1980, n. ${ }^{\circ} 32$ ). 
sus instituciones forales según lo dispuesto en el art. $3 .^{\circ}$ del Estatuto), y las recogidas en los muy relevantes artículos 37 y 41.

El artículo 37 del Estatuto dice que los Órganos Forales de los Territorios Históricos se regirán por el régimen jurídico privativo de cada uno de ellos (art. 37.1) y que lo dispuesto en el Estatuto no supone alteración de la naturaleza del régimen foral específico o de las competencias de los regímenes privativos de cada Territorio Histórico. Por su parte, el art. 37.3 establece un elenco de materias en las que los Territorios Históricos tienen competencia exclusiva: a) organización, régimen y funcionamiento de sus propias instituciones; b) elaboración y aprobación de sus Presupuestos; c) demarcaciones territoriales de ámbito supramunicipal que no excedan de los límites provinciales; d) régimen de los bienes provinciales y municipales, tanto de dominio público como patrimoniales o de propios y comunales; e) régimen electoral municipal.

En lo que respecta al artículo 41 del Estatuto, éste recoge todo lo relativo al actual sistema de Concierto Económico Vasco ${ }^{11}$, sistemaque se remonta a 1878, fecha del

${ }^{11}$ El Concierto Económico Vasco es elsistema que regula las relaciones de orden financiero y tributario entre la Comunidad Autónoma de Euskadi y el Estado. Hablando en general, y en lo que se refiere a los modelos de financiación autonómica existentes en el Estado español, frente al modelo de financiación de las Comunidades Autónomas de régimen común (al que pertenecen todas ellas menos las dos Comunidades Forales, es decir, la Comunidad Autónoma Vasca y la Comunidad Foral de Navarra), en el que es el Estado Central quien legisla, recauda y después distribuye los fondos entre las Comunidades Autónomas (modelo regulado por la Ley Orgánica 8/1980, de 22 de septiembre, de Financiación de las Comunidades Autónomas — la denominada LOFCA-), existe otro modelo de financiación, el de las dos Comunidades Forales, que funciona justo al revés, de tal manera que son ellas y no el Estado, quienes legislan y recaudan los tributos y contribuyen después a las cargas generales que son competencia del Estado con una cantidad, denominada cupo (en el caso de la Comunidad Autónoma Vasca) o aportación (en el caso de la Comunidad Foral de Navarra). El sistema de financiación de estas dos Comunidades forales, que responde a principios similares, recibe el nombre de Concierto Económico en Euskadi y se encuentra regulado en la Ley 12/2002, de 23 de mayo (y sus sucesivas modificaciones, siendo la última de ellas mientras escribo estas líneas, la que ha tenido lugar por Ley 10/2017, de 28 de diciembre).

Sobre el sistema de Concierto Económico Vasco, existe también una numerosa bibliografía. Como ocurre con el tema de los derechos históricos y dado el formato de este artículo, sólo puedo recoger algunas de las aportaciones doctrinales más relevantes. Entre ellas destacan: ALONSO ARCE, I. (2003), El Concierto Económico Vasco: la renovación de 2002, fuentes documentales, Bilbao, AD CONCORDIAM; ALONSO ARCE, I. (coord.) (2003); Reflexiones en torno a la renovación del Concierto Económico, Bilbao, AD CONCORDIAM; ALONSO ARCE, I. (2010), El Concierto Económico en Europa, Oñati, Instituto Vasco de Administración Pública; ALONSO OLEA, E. (1995), El Concierto Económico (1878-1937). Orígenes y formación de un Derecho Histórico, Oñati, Instituto Vasco de Administración Pública); ATXABAL RADA, A. / MUGURUZA ARRESE, J. (2006), Recopilación del Concierto Económico Vasco. Legislación, jurisprudencia y bibliografía (1981-2004), Bilbao, AD CONCORDIAM; DE LA HUCHA CELADOR, F. (2006), El régimen jurídico del Concierto Económico, Bilbao, AD CONCORDIAM; ESTECHA Y MARTÍNEZ, J.M. (1902), Régimen político y administrativo de las Provincias Vasco-Navarras, Bilbao, Imprenta Provincial; FERNÁNDEZ BARBADILLO, P.M. (2004), «El Concierto Económico: ¿pacto entre iguales o concesión?», Revista de Estudios Políticos, núm. 124, págs. 207-224; LAMBARRI GÓMEZ, C. / LARREA JIMÉNEZ DE VICUÑA, J.L. (1991), El Concierto Económico, Oñati, Instituto Vasco de Administración Pública; LÓPEZ BASAGUREN, A., «El Concierto Económico y la financiación de la Comunidad Autónoma del País Vasco. Entre mito y realidad», en GARCÍA HERRERA, M.A.,/ VIDAL BELTRÁN, 
primer Concierto, y afirma que las instituciones competentes de los Territorios Históricos: i)podrán mantener, establecer y regular, dentro de su Territorio, el régimen tributario, atendiendo a la estructura general impositiva del Estado, a las normas que para la coordinación, armonización fiscal y colaboración con el Estado se contengan en el propio Concierto, y a las que dicte el Parlamento Vasco para idénticas finalidades dentro de la Comunidad Autónoma; ii) que la exacción, gestión, liquidación, recaudación e inspección de todos los impuestos, salvo los que se integran en la Renta de Aduanas y los que actualmente se recaudan a través de Monopolios Fiscales, se efectuará dentro de cada Territorio Histórico, por las respectivas Diputaciones Forales, sin perjuicio de la colaboración con el Estado y su alta inspección; iii) que las instituciones competentes de los Territorios Históricos adoptarán los acuerdos pertinentes con objeto de aplicar en sus respectivos Territorios las normas fiscales de carácter excepcionaly coyuntural que el Estado decida aplicar al Territorio común, estableciéndose igual período de vigencia que el señalado para éstas.

J.M. (2005), El Estado autonómico: integración, solidaridad y diversidad, Madrid, INAP-Colex, vol. I, págs. 619-634; LARRAZABAL BASAÑEZ, S., «Encaje constitucional y estatutario del Concierto Económico como actualización de los derechos históricos», en VV.AA., El Concierto Económico ayer, hoy y mañana, Vitoria-Gasteiz, Parlamento Vasco, págs. 49-67; LÓPEZ BASAGUREN, A. (2006), «El Concierto Económico Vasco: del mito a la realidad», en VV.AA., El Concierto Económico a debate, Vitoria-Gasteiz, Diputación Foral de Álava, págs. 81-103; MARTÍNEZ ETXEBERRIA, G., La defensa jurídica de un derecho histórico paradigmático: el Concierto Económico Vasco, Bilbao, Departamento de Hacienda y Finanzas de la Diputación Foral de Bizkaia / Universidad de Deusto, 2014; MARTÍNEZ SIERRA, J.M. (2004), «El Concierto Económico y los derechos forales en sede judicial europea», Revista Española de Derecho Constitucional, núm. 72, págs. 235-264; MEDINA GUERRERO, M. (1991), Los regímenes financieros forales en la Constitución de 1978, Oñati, Instituto Vasco de Administración Pública; RUIZ ALMENDRAL, V. (2008), « ¿Vuelta a la casilla de salida? El concierto económico vasco a la luz del ordenamiento comunitario», Revista Española de Derecho Europeo, núm. 28, págs. 499-528; SERRANO GAZTELURRUTIA, S. (2012), El Concierto Económico Vasco ante el Juez Comunitario, Oñati, Instituto Vasco de Administración Pública; URIARTE SANTAMARINA, P.L. (2014), «Recuperación plena del Concierto Económico e inclusión en el marco constitucional y estatutario. Planteamiento del Concierto Económico actual» en VV.AA. (2014), El Concierto Económico ayer, hoy y mañana, Vitoria-Gasteiz, Parlamento Vasco, págs. 69-122; URIARTE SANTAMARINA, P.L. (2015), El Concierto Económico Vasco: una visión personal, Bilbao. 11 volúmenes. Descargable en http://www.elconciertoeconomico.com/la-obra/ (última consulta, 19 de febrero de 2018); VICARIO Y PEÑA, N. (1997), Los Conciertos Económicos de las Provincias Vascongadas, Reedición en «Clásicos de la Hacienda Foral», Bilbao, Diputación Foral de Bizkaia. VV.AA. (2006), Congreso Internacional. Concierto Económico Vasco y Europa, Bilbao, AD CONCORDIAM; VV.AA. (2015), El Concierto Económico: los retos actuales, Vitoria-Gasteiz, Parlamento Vasco; ZABALA Y ALLENDE, F. de (1927), El Concierto Económico, ¿qué ba sido - qué es - qué debe ser?, Bilbao, La Editorial Vizcaína; ZUBIRI ORIA, I. (2003), «El nuevo Concierto Económico: características básicas», Revista de Derecho Histórico de Vasconia. Notitiae Vasconiae, núm. 2, págs. 727-754; ZUBIRI ORIA, I. (2003), «La reforma del Concierto Económico: lecciones de la experiencia pasada», en ALONSO ARCE, I. (2003), Reflexiones en torno a la renovación del Concierto Económico, op. cit., págs. 115-127; ZUBIRI ORIA, I. (2015), «Un análisis del sistema foral de la Comunidad Autónoma del País Vasco y sus ventajas durante la crisis», Papeles de Economía española, núm. 143, págs. 205-224; ZURITA LAGUNA, A. (1985), «Notas al Concierto Económico», Revista de Estudios Políticos, núms. 46-47, págs. 633642; ZURITA SAENZ DE NAVARRETE, M. (1977), Cien años de Concierto Económico, Vitoria-Gasteiz, Diputación Foral de Álava.

N.o 103, septiembre-diciembre 2018, págs 303-330 
Por su parte, el artículo 49 del Concierto establece que la aportación del País Vasco al Estado consistirá en un cupo global, integrado por los correspondientes a cada uno de sus Territorios Históricos como contribución a todas las cargas del Estado que no asuma la Comunidad Autónoma del País Vasco. Y el artículo 50, establece que cada cinco años, mediante Ley votada por las Cortes Generales, y previo acuerdo de la Comisión Mixta de Concierto Económico, se procederá a determinar la metodología de señalamiento del cupo que ha de regir en dicho quinquenio. Esta ley es la denominada coloquialmente «Ley quinquenal del Cupo ${ }^{12}$

Evidentemente, dado que cada uno de los tres Territorios Históricos Vascos y no el Parlamento Vasco es el competente para aprobar su normativa tributaria mediante Normas Forales Tributarias, y como acabamos de ver, el propio Concierto prevé la coordinación, armonización fiscal y colaboración de las normativas forales fiscales de los Territorios Históricos, había que aprobar una Ley como es la Ley del Parlamento Vasco 3/1989, de 30 de mayo, de Armonización, Coordinación y Colaboración Fis$\mathrm{cal}^{13}$. Dicha Ley, prevé en su artículo 16, la existencia de un Órgano de Coordinación Tributaria (en adelante, OCT) en el que participan, de forma paritaria, tres representantes del Gobierno Vasco y tres de las Diputaciones Forales (uno por Territorio Histórico), y cuando se traten asuntos relativos a tributos locales, tres miembros en representación de los municipios. En el marco del Concierto Económico, el OCT es un ejemplo de cómo a pesar de la complejidad del modelo territorial vasco, éste establece paradójicamente garantías adicionales de participación paritaria de las distintas instituciones, lo que, en mi opinión, puede redundar en la calidad democrática del sistema.

Volviendo a la regulación de las competencias de los Territorios Históricos, entre ellas las derivadas del régimen de Concierto Económico (art. 41 del Estatuto de Gernika) y las demás mencionadas más arriba, éstas constituyen el célebre «núcleo intangible» para la legislador vasco, pues forman parte de lo que el Tribunal Constitucional ha definido en su Sentencia 76/1988, de 26 de abril como la garantía institucional de la foralidad, que deriva de la Disposición Adicional Primera de la Constitución y de su amparo y respeto de los derechos históricos de los Territorios Forales. De ahí que, coherentemente, el Estatuto de Autonomía diga en su artículo 37.2, que lo dispuesto en el mismo no supone alteración de la naturaleza del régimen foral específico o de las competencias de los regímenes privativos de cada Territorio Histórico ${ }^{14}$.

12 Para el quinquenio 2017-2021, la metodología de señalamiento del cupo del País Vasco ha quedado establecida en la Ley 11/2017, de 28 de diciembre.

${ }^{13}$ La Ley aparece publicada en el Boletín Oficial del País Vasco, n. ${ }^{\circ}$ 109, de 9 de junio de 1989.

${ }^{14}$ La jurisprudencia del Tribunal Constitucional sobre estos temas que afectan directamente a los Territorios Forales se deriva de, por ejemplo, las siguientes Sentencias: 11/1984, de 2 de febrero; 16/1984, de 6 de febrero; 123/1984, de 18 de diciembre; 94/1985, de 29 de julio; 76/1988, de 26 de abril; 86/1988, de 3 de mayo; 214/1989, de 21 de diciembre; 140/1990, de 20 de septiembre; 159/1993, de 6 de mayo; 233/1999, de 16 de diciembre; 255/2004, de 22 de diciembre; 252/2005, de 11 de octubre; 148/2006, de 11 de mayo; 295/2006, de 11 de octubre; 31/2010, de 28 de junio; 208/2012, de 14 de noviembre; 207/2013, de 5 de diciembre; 110/2014, de 26 de junio; 171/2014, de 23 de 
Al referirse al artículo 37.2 del Estatuto, el Tribunal Constitucional, en su Sentencia 76/1988, de 26 de abril (fundamento jurídico $6 .^{\circ}$ ), dejó claro cómo debe interpretarse éste: de hecho, afirmó que el Estatuto puede limitar el régimen foral históricamente definido y su correspondiente elenco de derechos históricos, porque si no fuera así, no podría llevar a cabo ninguna actualización, pero a la vez, dijo también que

«... el artículo 37.2 lo que viene a establecer es que, tanto los poderes y atribuciones que se confieren a los nuevos órganos que se crean —las Instituciones Comunes - como el reparto competencial que se efectúa en relación con las instituciones centrales del Estado habrán de entenderse siempre sin menoscabo de la garantía del régimen foral y las inherentes competencias de los Territorios Históricos que el mismo Estatuto determina. Se trata, pues, de una regla de garantía e interpretación, que coloca en un lugar preferente, en cuanto a su respeto y protección, a los regímenes forales en su definición estatutaria, tanto frente a las Instituciones Comunes del País Vasco como a los poderes centrales del Estado; regímenes forales que el mismo Estatuto precisa en cuanto a cuál sea su contenido esencial, intocable por los poderes autonómicos o estatales».

De tal manera que

«el contenido de esa garantía foral, que aparece así como punto de referencia obligado para la aplicación e interpretación de las disposiciones del Estatuto de Autonomía, viene expresado en su artículo 37, apartados 3 y 4. Así, este artículo viene a precisar dos tipos de competencias que pertenecen a los Territorios Históricos...»,

entre las que cita en primer lugar, las competencias exclusivas que derivan directamente del Estatuto, es decir, las especificadas en el artículo 37.3, subapartados a) a e) y primer inciso del subapartado f), y en segundo lugar, un segundo grupo de competencias que habrán de precisarse a través de la actuación concreta de los poderes de la Comunidad, y que comprenden tanto competencias exclusivas que les sean transferidas (apartado 37.3. segundo inciso del subapartado f), sin que el Estatuto precise por parte de quién, así como el desarrollo normativo y la ejecución, dentro de su territorio, de las materias que el Parlamento Vasco señale.

La Sentencia continua diciendo que

«... aparecen asi definidos un núcleo intangible, por prescripción estatutaria, del contenido del régimen foral $-y$ que resulta por tanto ser el mínimo sin el que desaparecería la misma imagen de la foralidad-y además, un ámbito de expansión de ese régimen, que se hace depender de la actuación de otros órganos. Se contempla pues la posibilidad de transferencia o atribución de competencias adicionales al núcleo de la foralidad, competencias que pueden derivar, bien del Estatuto de Autonomía, bien de los procedimientos previstos en el artículo 150.1 y 2, de la Constitución» (fundamento jurídico 6..$^{\circ}$.

octubre y 173/2014, de 23 de octubre; 118/2016, de 23 de junio; 203/2016, de 1 de diciembre; 113/2017, de 16 de octubre; Auto 150/2017, de 14 de noviembre y Sentencia de 8 de febrero de 2018 -aún sin número de orden cuando escribo estas líneas-. A este respecto, puede consultarse MARTÍNEZ ETXEBERRIA, G., La defensa jurídica de un derecho bistórico paradigmático: el Concierto Económico Vasco, op. cit., págs. 29-88. 
En todo caso, hay que advertir que en el Estatuto de Autonomía de Gernika no se estableció un reparto rígido de competencias entre las Instituciones Comunes y los Territorios Históricos, sino que estableció un mecanismo abierto y flexible. Ello explica que, como ha escrito el Profesor Edorta COBREROS, las normas estatutarias que atribuyen competencias a los Territorios Históricos se encuentren desperdigadas a lo largo del texto estatuario y que en éste no aparezca prevista ninguna Ley específicamente destinada a establecer con carácter general el reparto competencial interno. ${ }^{15}$

\subsection{La distribución de competencias en la Ley de Territorios Históricos}

Y como el Estatuto no recoge un detallado y exhaustivo reparto de competencias entre las Instituciones Comunes de la Comunidad Autónoma y los Órganos Forales de los Territorios Históricos y tampoco contempla expresamente una Ley de distribución de competencias entre dichas Instituciones, hubo que hacer esta distribución a través de una Ley ordinaria del Parlamento Vasco, ya que el Estatuto tampoco prevé ningún tipo de leyes especiales o de mayoría cualificada, a diferencia de lo que ocurre en otros Estatutos de Autonomía ${ }^{16}$.

Esta Ley ordinaria del Parlamento Vasco, es la Ley del Parlamento Vasco 27/1983, de 25 de noviembre, de Relaciones entre las Instituciones Comunes de la Comunidad Autónoma y los Órganos Forales de sus Territorios Históricos (más conocida como Ley de Territorios Históricos o LTH, denominaciones que seguiré en adelante ${ }^{17}$ ), que es la encargada de desarrollar el Estatuto de Autonomía en lo relativo al reparto de competencias entre las Instituciones Comunes del País Vasco y las de los Órganos Forales de los Territorios Históricos que lo componen, según se prevé en su art. $1 .{ }^{18}$

15 COBREROS MENDAZONA, E. (2006), «La modificación expresa de la Ley de Territorios Históricos como requisito para reducir las competencias de los Órganos Forales», Revista Vasca de Administración Pública, núm. 75, pág. 51.

16 Por ejemplo: el Estatuto catalán (Ley Orgánica 6/2006, de 19 de julio, de reforma del Estatuto de Autonomía de Cataluña), en su art. 62.2, que prevé las leyes de desarrollo básico del Estatuto, cuya aprobación, modificación y derogación requiere el voto favorable de la mayoría absoluta del Pleno del Parlamento en una votación final sobre el conjunto del texto, salvo que el Estatuto establezca otra. Una previsión similar podemos encontrarla en el art. 108 del Estatuto andaluz (Ley Orgánica 2/2007, de 19 de marzo, de reforma del Estatuto de Autonomía de Andalucía). Por su parte, el art. 20.dos de la Ley Orgánica 13/1982, de 10 de agosto, de Reintegración y Amejoramiento del Régimen Foral de Navarra (en adelante, LORAFNA), exige mayoría absoluta para su a aprobación, en una votación final sobre el conjunto del Proyecto, las leyes forales expresamente citadas en la LORAFNAy aquellas otras que sobre organización administrativa y territorial determine elReglamento de la Cámara.

${ }^{17}$ Publicada en el Boletín Oficial del País Vasco, n. ${ }^{\circ}$ 182, de 10 de diciembre de 1983.

${ }_{18}$ GONZÁLEZ DE ZÁRATE LORENTE, R. (2017), El ordenamiento político-administrativo de los Territorios Forales de Euskadi...op.cit., págs. 225-231 y 237-305. 
El Título I de la LTH establece el reparto concreto de competencias entre las Instituciones Comunes de la Comunidad Autónoma y los Órganos Forales de los Territorios Históricos. En él se desarrollan las competencias del «núcleo intangible de la foralidad», además de aquellas propias de la Comunidad Autónoma que el Parlamento Vasco ha decidido transferir a los Territorios Históricos. En el artículo 7 se recogen las materias que son competencia de los Territorios Históricos y en el artículo 8 aparecen cuáles son las potestades que les corresponden en dichas materias, que pueden ser exclusivas, de desarrollo normativo y ejecución o únicamente de ejecución, con una cláusula de cierre, la del art. 6.1, que establece una cláusula residual a favor de las Instituciones Comunes (es decir el Parlamento y el Gobierno Vascos), en consecuencia con lo afirmado por el Preámbulo de la LTH que afirma que «el fondo de poder en la Comunidad Autónoma reside en sus Instituciones Comunes». ${ }^{19}$

Finalmente, el artículo 6.2 reserva en exclusiva al Parlamento Vasco la facultad de dictar normas con rango formal de Ley, lo cual supone que las normas dictadas por las Asambleas de cada uno de los tres Territorios Históricos (las Juntas Generales), denominadas «Normas Forales», no tienen rango formal de ley y por ello, en la mayoría de los casos, estas Normas Forales se impugnan ante la jurisdicción ordinaria contencioso-administrativa, excepto las Normas Forales fiscales, que tampoco tienen rango formal de ley pero regulan materias habitualmente reservadas a la ley (como los tributos). Dada la especialidad del sistema de fuentes vasco ${ }^{20}$ y del núcleo intangible de la foralidad, al que me acabo de referir, estas Normas Forales fiscales no pueden ser dictadas por el Parlamento Vasco, que es el único que puede dictar normas con rango formal de ley porque no son competencia suya sino que han de ser dictadas por las Juntas Generales, que son las competentes en la materia, pero que a su vez no pueden dictar Leyes formales sino solamente Normas Forales.

Como esas Normas Forales fiscales no tienen rango formal de Ley pero regulan materias que tradicionalmente son reguladas en otros ordenamientos jurídicos por ley (por ejemplo en el Estado o en la Comunidad Foral de Navarra), son controlables no por los Tribunales ordinarios de la jurisdicción contencioso-administrativa, sino directamente por el Tribunal Constitucional, según prevén el art. 3 d) de la Ley 29/1988, de 13 de julio, reguladora de la Jurisdicción Contencioso-Administrativa, el artículo 9.4 de la Ley Orgánica 6/1985, de 1 de julio, del Poder Judicial y la Disposición Adicional Quinta de la Ley Orgánica del Tribunal Constitucional, introducidas estas últimas mediante la reforma de la Ley Orgánica del Tribunal Constitucional que tuvo lugar por Ley Orgánica 1/2010, de 19 de febrero, lo que, como era de

19 Párrafo 8. ${ }^{\circ}$ del Preámbulo de la LTH.

20 A este respecto, es de obligada consulta el texto de JIMÉNEZ ASENSIO, R. (1997),» El sistema de fuentes del derecho en la Comunidad Autónoma del País Vasco como ordenamiento asimétrico», Revista Vasca de Administración Pública, núm. 47-II, págs. 127-171. 
esperar, dio lugar a una larga polémica doctrinal ${ }^{21}$ en torno a la naturaleza jurídica y al rango de las Normas Forales emanadas de las Juntas Generales de los Territorios Históricos, polémica que el Tribunal Constitucional ha venido a zanjar avalando la constitucionalidad de la Ley Orgánica 1/2010, en una conocida Sentencia interpretativa, la Sentencia 118/2016, de 23 de junio.

Pero no acaban ahí las especialidades del sistema vasco de distribución de competencias entre Instituciones Comunes y Órganos Forales. Hay un «más difícil todavía»: tal y como escribí en su momento ${ }^{22}$, a pesar del «núcleo intagible», una de las partes, el Parlamento Vasco, el único que tiene competencias para dictar disposiciones con rango de ley, puede modificar a su gusto y de manera unilateral el sistema de reparto de competencias entre Instituciones Comunes y Territorios Históricos, simplemente modificando la LTH, que es una ley ordinaria que no requiere ninguna mayoría específica, siempre que, eso sí, su modificación no afecte a las materias que forman parte ese «núcleo de la foralidad» que resulta intocable ${ }^{23}$, pues estas materias constituyen, como acabamos de ver y utilizando la terminología que el propio Preámbulo de la LTH emplea, «...zonas de poder exentas de Ley de Parlamento» ${ }^{24}$.

En definitiva, la LTH, que es una Ley ordinaria del Parlamento Vasco que desarrolla nada menos que el Estatuto de Autonomía en materia de distribución interna de competencias, puede aumentar o disminuir las competencias de los Territorios Históricos salvo, como hemos visto, las pertenecientes al «núcleo intangible de la foralidad». Pues bien, a pesar de su importancia, la LTH no tiene ninguna «inmunidad» frente a cualquier otra Ley del Parlamento Vasco y puede ser modificada por el legislador vasco en cualquier momento y por mayoría simple.

Y como era previsible, se ha intentado su modificación tácita por otras leyes posteriores del Parlamento Vasco, lo que ha planteado un grave problema de inseguridad jurídica, problema creado por otras Leyes del Parlamento Vasco posteriores a la LTH que han derogado no expresa sino tácitamente algunos artículos de la misma (aplicando el criterio general de que la ley posterior deroga la ley anterior). Frente a estos abusos, para evitar las modificaciones o derogaciones implícitas o tácitas de la LTH por parte de otras leyes posteriores, como había ocurrido anteriormente, y evitar por ende modificaciones fraudulentas y un tanto «clandestinas» del sistema de repar-

${ }^{21}$ La cuestión ha hecho» correr ríos de tinta doctrinal.» Un adecuado estudio del tema, puede encontrarse en MARTÍNEZ ETXEBERRIA, G., La defensa jurídica de un derecho bistórico paradigmático: el Concierto Económico Vasco, op. cit., págs. 195-264 y en GONZÁLEZ DE ZÁRATE LORENTE, R., El ordenamiento político-administrativo de los Territorios Forales de Euskadi, op. cit., págs. 327-347 y 369-391.

${ }^{22}$ LARRAZABAL BASAÑEZ, S., « ¿26 años no es nada...? Luces y sombras en la distribución de competencias entre las Instituciones Comunes de la Comunidad Autónoma del País Vasco y la de sus Territorios Históricos», op. cit., págs. 713-714.

23 Véase, en este sentido, la Decisión 5/2003, de 3 de noviembre, de la Comisión Arbitral, en el caso de las cuestiones de competencia planteadas por las instituciones del Territorio Histórico de Álava respecto del Proyecto de Ley de Ordenación Vitivinícola (publicada en el Boletín Oficial del País Vasco de 20 de febrero de 2004, n. $\left.{ }^{\circ} 35\right)$.

24 Párrafo 7. ${ }^{\circ}$ del Preámbulo de la LTH. 
to de competencias entre Instituciones Comunes y Órganos Forales de los Territorios Históricos, la Comisión Arbitral vasca ha reaccionado con firmeza, y ha exigido parapara su validez, una reforma expresa de la $\mathrm{LTH}^{25}$.

Al hilo de este comentario, tengo que explicar, siquiera mínimamente y sobre todo para todas aquellas personas que no estén familiarizadas con el sistema jurídico-institucional vasco, que la Comisión Arbitral es un órgano absolutamente único en nuestro ordenamiento jurídico público, previsto en el artículo 39 del Estatuto de Gernika, un órgano independiente, paritario, es decir, compuesto por tres vocales nombrados por el Gobierno Vasco y otros tres por las Diputaciones Forales (uno por cada Diputación Foral) y presidido por el Presidente del Tribunal Superior de Justicia del País Vasco. Un órgano diseñado para solucionar los conflictos y cuestiones de competencia que puedan surgir entre las Instituciones Comunes y las de los Territorios Históricos $\mathrm{Vascos}^{26}$, y entre cuyas relevantes funciones que lo asemejan a una

${ }^{25}$ La Comisión Arbitral ha dicho en su Decisión 5/2003, de 3 de noviembre, que el sistema da lugar a «... una disociación entre la naturaleza angular de la LTH por razón de su contenido y su envoltorio legal formal, siendo la modificación de éste por una ley del Parlamento Vasco elemento suficiente para alterar el contenido de aquella». Por eso, y en aras de la seguridad jurídica, "... la alteración del esquema competencial de la LTH, de su contenido material, requiere desde un punto de vista formal una norma con rango de ley dictada por el Parlamento Vasco, que articule de forma directa, expresa y fundada dicha modificación, ya que de lo contrario, la propia LTH se vería desprovista de su propia función de encaje competencial básico en la Comunidad Autónoma del País Vasco» (f.j.2. $\left.{ }^{\circ}\right)$.

El criterio contenido en esta Decisión de la Comisión Arbitral, ha sido sostenido de forma reiterada posteriormente en las Decisiones: $1 / 2005$, de 8 de febrero, f.j. $1 .^{\circ}$, relativa a las cuestiones de competencia planteadas por las Juntas Generales de Álava y la Diputación Foral en relación con el Proyecto de Ley de Aguas ( BOPV, n. ${ }^{\circ} 40$, de 28 de febrero de 2005) ; 1/2008, de 20 de octubre, f.j. 3. ${ }^{\circ}$, relativa cuestiones de competencia planteada por las Diputaciones Forales de Bizkaia y Álava, y por las Juntas Generales de Álava en relación con el Proyecto de Ley Municipal de Euskadi ( BOPV, n. . 236, de 10 de diciembre de 2008 );3/2012, de 19 de abril , f.jA, cuarto, 11, relativa a las cuestiones de competencia planteadas por las Juntas Generales del Territorio Histórico de Álava, la Diputación Foral de Bizkaia y la Diputación Foral de Álava, en relación con el proyecto de Ley Municipal de Euskadi. (BOPV, n. ${ }^{\circ} 115$, de 13 de junio de 2012) y en la reciente1/2016, de 1 de agosto, f.j.2. ${ }^{\circ}$, relativa a las cuestiones de competencia 1/2015, 2/2015, 3/2015, 4/2015 planteadas, respectivamente, por la Diputación Foral de Bizkaia, Juntas Generales de Álava, Diputación Foral de Gipuzkoa y Diputación Foral de Álava, en relación con la «Proposición de Ley sobre la Organización Institucional Interna de la Comunidad Autónoma del País Vasco» ( BOPV, n. ${ }^{\circ}$ 206, de 31 de octubre de 2016).

${ }^{26}$ Ley 13/1994, de 30 de junio, por la que se regula la Comisión Arbitral (Boletín Oficial del País Vasco de 27 de julio de 1994, n. ${ }^{\circ}$ 142). Para un estudio más detallado de la naturaleza especial y a las competencias de la Comisión Arbitral Vasca, en el que, por las limitaciones de este texto, no puedo entrar ahora, pueden consultarse, por ejemplo: ARLUCEA RUIZ, J.E. (1990), «La Comisión Arbitral del Estatuto Vasco», Revista Vasca de Administración Pública, núm. 28, págs. 19-60; ARLUCEA RUIZ, J.E. (1991), «Las Comisiones Arbitrales», en VV. AA., Estudios sobre el Estatuto de Autonomía del País Vasco, Oñati, Instituto Vasco de Administración Pública, Tomo IV, págs. 1721-1732; BALZA AGUILERA, J. (1985), «La naturaleza jurídica de las Comisiones Arbitrales (el artículo 39 del Estatuto de Autonomía del País Vasco», Revista Vasca de Administración Pública, núm. 12, págs. 29-57; COBREROS MENDAZONA, E. (2005), «La inimpugnabilidad de las Resoluciones de la Comisión Arbitral del País Vasco», Revista de Administración Pública, núm. 167, págs. 47-96; COBREROS MENDAZONA, E. (2008), «Un asunto sin resolver: la cuestionada constitucionalidad de la irrecurribilidad ante la jurisdicción contencioso-administrativa de las 
especie de «Tribunal constitucional interno», puede decidir no sólo a quién corresponde la competencia discutida sino incluso en algunos casos obligar a retirar Proyectos y Proposiciones de Ley en tramitación en Parlamento Vasco y Proyectos o Proposiciones de Norma Foral en tramitación en las Juntas Generales si considera que son contrarios al sistema de reparto de competencias entre Instituciones Centrales de la Comunidad Autónoma Vasca y las Instituciones de los Territorios Históricos ${ }^{27}$. La institución es novedosa y única en nuestro entorno, pero absolutamente imprescindible en un modelo en el que hay que garantizar las competencias de los distintos niveles institucionales del País, tanto de las Instituciones Comunes como las de los propios Territorios Históricos, y en el que hay que asegurar la garantía institucional de la foralidad, derivada de la protección de los derechos históricos, protegidos por la Constitución española y por el Estatuto de Autonomía Vasco, tal y como la ha definido el Tribunal Constitucional en una abundante jurisprudencia al respecto, a la que me he referido anteriormente.

resoluciones de la Comisión Arbitral», Revista Vasca de Administración Pública, núm. 81, págs. 169-179; COBREROS MENDAZONA, E. (2009), Escritos sobre la Comisión Arbitral, Oñati, Instituto Vasco de Administración Pública; ETXEBARRIA ETXEITA, I.J. (1991), «Comisiones Arbitrales», en Estudios sobre el Estatuto de Autonomía del País Vasco, op. cit., págs. 1733-1744; FLÓREZ TURRADO, F.J. (2012), «Comisión arbitral del País Vasco y control autonómico de constitucionalidad, Revista Vasca de Administración Pública, núm. 94, págs. 59-93; GARCÍA HERRERA, M.A. (1981), «Instituciones autonómicas centrales e instituciones forales de los Territorios Históricos: la Comisión Arbitral del Estatuto Vasco», Revista Española de Derecho Administrativo, núm. 30, págs. 529-595; GARCÍA HERRERA, M.A. / LÓPEZ BASAGUREN, A. (1995), «Problemas en torno a los efectos de las decisiones de la Comisión Arbitral», Revista Vasca de Administración Pública, núm. 41, págs. 14-80; GARCÍA URETA, A. (2003), La Comisión Arbitral del País Vasco. Régimen jurídico y resoluciones (1999-2002), Oñati, Instituto Vasco de Administración Pública; LAMARCA ITURBE, I. (1995), «La Comisión Arbitral del País Vasco», Revista Vasca de Administración Pública, núm. 42, págs. 429-446; LARRAZABAL BASAÑEZ, S. (2001), «Una institución peculiar de nuestro ordenamiento jurídico: laComisión Arbitral Vasca» enMORODO, R. I VEGA, P. de, Estudios de Teoría del Estado y Derecho Constitucional en honor de Pablo Lucas Verdú, MéxicoMadrid, Instituto de Investigaciones Jurídicas de la Universidad Nacional Autónoma de México / Facultad de Derecho de la Universidad Complutense, vol. IV, págs. 2581-2608; LEGUINA VILLA, J. (1981), «Los Territorios Históricos Vascos: poderes normativos y conflictos de competencias», Revista española de Derecho Constitucional, núm. 3, págs. 63-92; LEGUINA VILLA, J. (1995), «La Ley 13/1994 reguladora de la Comisión Arbitral y el artículo 39 del Estatuto de Autonomía del País Vasco», Revista Vasca de Administración Pública, núm. 41, págs. 251-260; LÓPEZ BASAGUREN, A. (1991), «Las Comisiones Arbitrales» en VV.AA., Estudios sobre el Estatuto de Autonomía del País Vasco, Oñati, Instituto Vasco de AdministraciónPública, Vol. IV, págs. 1645-1698; MARISCAL, G. (2003), «La Comisión Arbitral», Boletín de la Academia Vasca de Derecho, núm. 1, págs. 4-30; URETA DOMINGO, J.C. (1983), «La superación arbitral de los conflictos: las Comisiones Arbitrales», en VV.AA., Primeras Jornadas de estudio del Estatuto de Autonomía del País Vasco, Oñati, 1983, vol. III, págs.1419-1473;

27 Sin embargo, sus funciones actuales en el caso de los proyectos o proposiciones normativas, terminan una vez que los textos entran en las respectivas Cámaras, pero no puede controlar cómo quedan los proyectos normativos si en la tramitación posterior en las distintas Cámaras se introducen enmiendas que van en contra del reparto de competencias previstos en el ordenamiento vasco. Convendría que para evitar posibles fraudes, para «burlar» la labor de la Comisión Arbitral, su control se extendiese también no sólo a los textos iniciales, sino también a los textos enmendados, tal y como se recoge en el «Informe sobre Análisis y Funcionamiento Institucional en la Comunidad Autónoma de Euskadi», op. cit., pág. 77. 
Como el control que realiza la Comisión Arbitral es un control previo (es decir, que actúa antes de que dichas normativas sean aprobadas o produzcan efectos), supone también en cierto modo un nuevo ejemplo de diseño de un órgano institucional de control que garantiza de algún modo la calidad democrática, impidiendo que algunas instituciones vascas puedan dotarse de normativa que no respeta las competencias de las demás.

Pero como ya hemos visto, en nuestro sistema de vertebración interno, salvo el núcleo de la foralidad que resulta intocable, las competencias de los Territorios Históricos pueden aumentar o disminuir. Pueden aumentar, o bien modificando expresamente la propia LTH, como ocurrió, por ejemplo, en 1993, en materia de Planeamiento Urbanístico (Ley 5/1993, de 16 de julio) ${ }^{28}$, bien mediante la modificación de la Ley del Concierto Económico ${ }^{29}$, bien a través de una Ley sectorial del Parlamento Vasco que, por seguridad jurídica, debería modificar también y de manera expresa la LTH para incluir esa nueva competencia, o bien mediante una Ley del Estado que atribuyese a los Territorios Históricos alguna competencia que hasta entonces correspondía al Estado. ${ }^{30}$

Pero al igual que las competencias de los Territorios Históricos pueden aumentar, también pueden disminuir, a través de modificaciones expresas de la LTH, siempre que no se trate de las competencias intocables a las que me he referido anteriormente, salvo que se produzca una modificación constitucional o estatutaria (y si la modificación sólo es estatutaria, respetando en todo caso el contenido de la Disposición Adicional Primera de la Constitución). De hecho, esta disminución de competencias ya se ha producido, por ejemplo, con la Ley 1/2006, de 23 de junio, de aguas ${ }^{31}$, ha modificado los apartados a) 10, y b) 1 y 4 del art. 7 de la LTH para limitar las competencias de los Territorios Históricos con las nuevas competencias que la Ley otorga a la Agencia Vasca del Agua (URA), que pertenece al ámbito competencial de las Instituciones Comunes de la Comunidad Autónoma de Euskadi.

Además del reparto competencial, la propia LTH establece entre los principios de actuación de las relaciones entre Instituciones Comunes del País Vasco y Órganos Forales de los Territorios Históricos, es decir, los principios de colaboración y solidaridad (art. 2.1), actuando las Administraciones vascas de acuerdo con los principios de eficacia y colaboración (art. 2.2), e incorpora de alguna manera técnicas típicas de

${ }^{28}$ Publicada en el Boletín Oficial del País Vasco de 20 de julio de 1993, n. ${ }^{\circ}$ 136. La Ley añadía dos párrafos al texto inicial de la LTH y afirmaba que también corresponde a los Territorios Históricosla aprobación de todos los instrumentos de Ordenación Urbanística, salvo los planes especiales en ejecución de competencias sectoriales atribuidas a las Instituciones Comunes que desarrollen instrumentos de Ordenación Territorial o Urbanística.

29 Así lo estableció la Comisión Arbitral en su Decisión 2/2003, de 17 de marzo, aunque dos de sus miembros opinaron lo contrario, según consta en su voto particular (publicada en el Boletín Oficial del País Vasco de 20 de octubre de 2003, n. ${ }^{\circ} 204$ ).

30 Pensemos, por ejemplo, en la Disposición Adicional 2. ${ }^{\text {, }}$, párrafo 7. ${ }^{\circ}$, de la Ley 7/1985, de 2 de abril, de Bases del Régimen Local (publicada en el Boletín Oficial del Estado de 3 de abril de 1985, n. ${ }^{\circ} 80$ ), en relación con la convocatoria de concursos y nombramiento de funcionarios locales con habilitación de carácter nacional.

31 Publicada en el Boletín Oficial del País Vasco de 19 de julio de 2006, n. ${ }^{\circ} 137$. 
los modelos de federalismo cooperativo, recogiendo la posibilidad de que el Gobierno Vasco y las Diputaciones Forales, puedan realizar convenios de prestación de servicios (art. 5.1. LTH), incluyendo deberes de información acerca de Convenios ya suscritos (un ejemplo de un principio federal clásico de lealtad y solidaridad mutua, que «se halla reconocido en el carácter de interdependencia que se atribuye al sistema institucional vasco») y que al obligar a las distintas Administraciones a trabajar juntas, favorece también mayores niveles de calidad democrática. ${ }^{32}$

Por último, y al referirme a la LTH, no puedo dejar de hacer una breve mención a su título II, en el que se regulan las relaciones financieras entre la Hacienda General del País Vasco (perteneciente al Gobierno Vasco) y las Haciendas Forales (pertenecientes a cada una de las tres Diputaciones Forales vascas). Dado que son las Diputaciones Forales y no el Gobierno Vasco quienes recaudan los impuestos, son ellas las encargadas de realizar las aportaciones necesarias para financiar los gastos de todas las Administraciones Vascas de los tresniveles institucionales. Y así, los ingresos derivados de la gestión del Concierto Económico, una vez descontado el cupo a satisfacer al Estado, se distribuyen entre la Hacienda General del País Vasco y las Haciendas Forales de los Territorios Históricos, determinándose las aportaciones que estas últimas han de hacer a la primera. El reparto de los recursos a distribuir y el consiguiente cálculo de las aportaciones de cada Territorio se realiza en consideración a las competencias de las que las Instituciones Comunes y los Órganos Forales de los Territorios Históricos sean titulares (teniendo en cuenta también que los Territorios Históricos son los que proveen también la mayor parte de los recursos económico-financieros que se destinan a los Municipios vascos).

En resumen: son las instituciones de los Territorios Históricos (las Diputaciones Forales) las que recaudan y, por tanto, las que deben hacer las correspondientes aportaciones al Gobierno Vasco para financiar los servicios que éste presta en virtud de sus competencias (educación, sanidad, policía, etc.). Después de calcular cuánto tienen que pagar las Instituciones vascas al Estado, en virtud del Cupo, cuánto han de pagar las tres Diputaciones Forales al Gobierno Vasco y cuánto le toca pagar a cada Diputación Foral de esa cantidad, queda un último asunto: la financiación de los 251 municipios vascos. La mayor parte de los ingresos municipales dependen de las aportaciones que les hagan las Diputaciones Forales, puesto que sus tributos propios tienen una cuantía económica escasa y en todo caso insuficiente para garantizar un nivel de recursos aceptable para sufragar los importantes y crecientes servicios que prestan ${ }^{33}$.

32 Esto ocurre también con algunos mecanismos previstos en la Ley 7/1981, de 30 de junio sobre Ley deGobierno (Boletín Oficial del País Vasco, n. ${ }^{\circ}$ 46, de 27 de julio de 1981), que permite al Gobierno Vasco, autorizar y aprobar Convenios de la Comunidad Autónoma con los Territorios Históricos para la gestión de servicios propios de los Territorios Históricos. En relación con estos temas, puede consultarseel el Informe sobre el análisis y funcionamiento institucional en la Comunidad Autónoma de Euskadi, págs. 16 y ss.

33 Sobre la distribución de recursos entre las distintas instituciones vascas, pueden consultarse: ANSOATEGUI FERNÁNDEZ DE ARROYABE, I. (2018), La distribución de recursos entre las Haciendas del País Vasco: treinta y seis años de historia y una propuesta, Bilbao, AD CONCORDIAM; GALDEANO 
Todo ello se decide en el Consejo Vasco de Finanzas Públicas que, tras las últimas modificaciones introducidas en la LTH por la Ley 2/2016, de 7 de abril, de Instituciones Locales de Euskadi, es un órgano compuesto por nueve miembros, tres designados por el Gobierno Vasco, tres designados por las Diputaciones Forales (uno por cada Diputación Foral), y otros tres en representación de los municipios vascos (uno por cada Territorio Histórico) $)^{34}$, nombrados por el Lehendakari a propuesta de la Asociación vasca de municipios de mayor implantación (en este momento, la Asociación de Municipios Vascos —EUDEL_- $)^{35}$. Sus acuerdos se adoptan, en principio, por mayoría absoluta salvo que la Ley prevea otra cosa (y dependiendo de los asuntos, en algunos casos se exige que dicha mayoría esté compuesta por al menos un representante de dos o incluso de los tres niveles institucionales vascos).

Éste es otro claro ejemplo de la complejidad del sistema político-territorial vasco, que ha de mantener un delicado equilibrio entre Instituciones Comunes e Instituciones de los Territorios Históricos. Esta gran complejidad es el precio a pagar por la estabilidad del sistema institucional vasco, pero el sistema, a pesar de todo, funciona y paradójicamente, obliga a todos los actores institucionales vascos, muy plurales y con intereses encontrados desde el punto de vista territorial e ideológico-político, a llegar a acuerdos (incluidos los relativos al siempre polémico tema de la financiación) aunque en algunos casos sean acuerdos adoptados «a regañadientes», pero acuerdos al fin y al cabo, y todo ello a pesar de sus a menudo profundas diferencias, con el objetivo de que el sistema no se bloquee, bloqueo que no interesa a nadie, lo que finalmente, produce el beneficioso efecto de exigir la participación de todas las instituciones y sensibilidades en la toma de decisiones que, en definitiva, afectan a todas las instituciones vascas, lo que favorece el control recíproco entre ellas, disminuye las «tentaciones» de corrupción, y en consecuencia, aumenta la calidad democrática del sistema.

LARIZGOTIA, I. / ZURUTUZA MUJIKA, S. (2017), «Financiación de las entidades locales de Euskadi en el marco de la Ley 2/2016, de Instituciones Locales de Euskadi», Revista Vasca de Administración Pública, núm. 107-II, págs. 471-501; URKIOLA FERNÁNDEZ, A. (2017), La redistribución entre Territorios Históricos dentro del Sector Público Vasco, Oñati, Instituto Vasco de Administración Pública.

${ }^{34}$ En lo que se refiere a la designación de los tres representantes de los Municipios vascos —uno por cada Territorio Histórico— y según lo establecido por el nuevo art. 28.10 de la LTH, se atenderá a criterios territoriales y de género y a la salvaguarda de la presencia de municipios de diferentes tamaños, de modo que al menos un tercio de los representantes municipales sean electos de municipios con población inferior a 5.000 habitantes.

35 El Consejo Vasco de Finanzas Públicas aprueba la metodología de distribución de recursos y la determinación de las aportaciones de cada Territorio Histórico a los gastos presupuestarios de la Comunidad Autónoma en principio para cinco ejercicios presupuestarios. Después, el Gobierno Vasco eleva al Parlamento Vasco para su aprobación el correspondiente Proyecto de Ley, que incorpora la metodología que hubiere acordado el Consejo Vasco de Finanzas Públicas. Se trata de un Proyecto de Ley de artículo único, que el Parlamento Vasco aprueba o rechaza en bloque, sin que se admitan enmiendas: es la conocida popularmente como «Ley de Aportaciones». Actualmente sigue vigente la Ley 2/2007, de 23 de marzo, de Metodología de Distribución de Recursos y de Determinación de las Aportaciones de las Diputaciones Forales a la Financiación de los Presupuestos de la Comunidad Autónoma del País Vasco aplicable al período 2007-2011, prorrogada hasta que haya una nueva Ley. 


\section{LAS COMPETENCIAS DE LAS INSTITUCIONES LOCALES DE EUSKADI}

Si ya era complicado establecer un sistema de distribución de competencias (y de adecuada financiación) entre las Instituciones Comunes de la Comunidad Autónoma y los Órganos Forales de los tres Territorios Históricos, el sistema se complica aún más al tener que insertar en el mismo el tercer nivel territorial de Euskadi, el compuesto por los Municipios y las demás instituciones locales vascas. Porque el modelo territorial vasco es tripartito y el círculo no estaba totalmente cerrado sin el nivel local. Es decir, faltaba por regular uno de las tres «pilares» del sistema: el municipal.

Y de hecho, el círculo no se ha cerrado hasta la aprobación en 2016 de la Ley de Instituciones Locales de Euskadi (en adelante, LILE) ${ }^{36}$, que desarrolla el art. 10.4 del Estatuto de Gernika, que establece que «la Comunidad Autónoma del País Vasco tiene competencia exclusiva en materia de régimen local y estatuto de los funcionarios del País Vasco y de su Administración Local, sin perjuicio de lo establecido en el artículo 149.1.8 de la Constitución».

La aprobación de la LILE ha puesto fin a un larguísimo proceso para intentar aprobar una Ley Municipal vasca, en el que hubo varios proyectos legislativos que se quedaron por el camino. Piénsese que el Estatuto de Autonomía es de 1979 y la LTH de 1983 y que se ha tardado más de 35 años en aprobar una Ley municipal, siendo como es una de las normas jurídicas más importantes para cerrar la vertebración territorial vasca junto al Estatuto y a la LTH. El retraso es tan llamativo, que hasta la Exposición de Motivos de la Ley se refiere a él en su apartado I.

Las razones para ello han sido bien explicadas por BAZAKO y ETXANOBE ${ }^{37}$ y se podrían resumir de la siguiente manera: porque en el Estatuto de Gernika quedó en segundo plano la referencia al nivel local a la hora de definir el sistema de vertebración territorial de Euskadi, en beneficio de los otros dos niveles institucionales (Instituciones Comunes de la Comunidad Autónoma y Órganos Forales de los Territorios Históricos); porque se dio prioridad a la LTH; porque la legislación básica del Estado en materia de régimen local acotaba estrechamente el margen del legislador vasco a la hora de regular el régimen local vasco, que se encontraba constreñido por tres frentes: la legislación básica del Estado cada vez más «intrusiva» en opinión de estos autores, la regulación estatutaria y la LTH, lo que «achicaba espacios», al ámbito municipal vasco; porque la garantía de la foralidad permitía a los Territorios Históricos —al amparo de cláusulas especiales expresamente recogidas en la legislación estatal básica del régimen localejercitar directamente competencias en importantes materias (organización, funcionamiento, personal, bienes y haciendas locales) y porque, en definitiva, había dos concep-

${ }^{36}$ Ley 2/2016, de 7 de abril, de Instituciones Locales de Euskadi, publicada en el Boletín Oficial del País Vasco, n. ${ }^{\circ}$ 70, de 14 de abril de 2017. Corrección de errores, publicada en el Boletín Oficial del País Vasco n. ${ }^{\circ} 123$, de 29 de junio de 2016).

37 BAZAKO ATUTXA, P. / ETXANOBE LANDAJUELA, E. (2015), «Ley municipal de Euskadi: ¿está vez sí?, Revista Vasca de Gestión de Personas y Organizaciones Públicas, núm. 8, págs. 67 y ss. 
ciones contrapuestas acerca de cómo entender el municipio en el seno del entramado institucional vasco, las que hacían pivotar el sistema en una regulación más «municipalista» y aquellas que preferían una mayor tutela de los municipios vascos por parte de los Territorios Históricos (más «foralista», llámemosla así).

En todo este tiempo, los entes locales vascos tuvieron que moverse en un marco jurídico precario, tal y como se explica en el párrafo primero de la Exposición de Motivos de la LILE, combinando la aplicación de Normas Forales de los Territorios Históricos (sobre todo en el ámbito tributario y económico-financiero), con la aplicación de la normativa básica del Estado en materia de régimen local, y de las leyes sectoriales aprobadas por el Parlamento Vasco (especialmente acerca de urbanismo, medio ambiente, servicios sociales, etc.).

Y la pregunta es inevitable: ¿y por qué en 35 años desde que echó a andar el Parlamento Vasco no fue posible aprobar una Ley Municipal Vasca y sí se pudo hacer en 2016? Pues hay varios factores que lo explican: la ratificación por el Reino de España de la Carta Europea de la Autonomía Local y los compromisos que ella comporta; la creciente presión del municipalismo vasco para que se aprobase de una vez por todas, una Ley municipal; las nuevas mayorías políticas surgidas tanto en las Instituciones Comunes como en las de los Territorios Históricos, la nueva configuración de la Asociación de Municipios Vascos (EUDEL) en la que, por primera vez, estaban representadas todas las sensibilidades políticas vascas y dos elementos, referidos a la normativa estatal: las reformas constitucional y legal en materia de sostenibilidad financiera y estabilidad presupuestaria y la Ley 27/2013, de 27 de diciembre, de Racionalización y Sostenibilidad de la Administración Local (en adelante, LRSAL), que era una Ley muy restrictiva de la autonomía local pero en la que, paradójicamente, gracias a las negociaciones políticas introducidas en su tramitación parlamentaria en las Cortes Generales, se introdujeron unas cláusulas especiales favorables para los Territorios Forales que podían y de hecho, están dando, «mucho juego», con lo que el legislador vasco ha podido articular un sistema de régimen local propio ${ }^{38}$.

Y si se me permite la expresión: ¿cómo fue posible el «milagro»?En este caso estamos en una auténtica labor de orfebrería jurídico-política, que algún día la sociedad vasca tendrá que agradecer expresamente a todos los que participaron en el proceso. En todo caso, se demuestra con hechos concretos que, una vez más, tal y como sostiene una gran parte de la doctrina, todo lo que se avance en interacción y colaboración entre los distintos niveles de gobierno, mejora la calidad democrática de las instituciones y de los procesos de toma de decisiones políticas fundamentales. En el caso vasco, creo que la aprobación de la LILE es un ejemplo claro de ello. De hecho, la participación y el acuerdo o al menos, el «no-bloqueo» de la aprobación de laLey por parte de los tres niveles institucionales vascos (Instituciones Centrales, Territorios Históricos y representantes municipales), hicieron posible

${ }^{38}$ LARRAZABAL BASAÑEZ, S. «Zumen hauekin... ekin lanari», op. cit., págs. 25-27; BAZAKO ATUTXA, P. / ETXANOBE LANDAJUELA, E., «Ley municipal de Euskadi», op. cit., págs. 69-70. 
su aprobación. Para entender cómo se sustanció el proceso, nada mejor que volverla Exposición de Motivos de la LILE.

En él se hace referencia a cómo todo el mundo sabía que la Ley tenía que «establecer un mínimo común denominador que concitase un acuerdo lo más amplio posible de la representación de las distintas sensibilidades políticas y de los tres niveles institucionales de Euskadi, pues todos los agentes políticos e institucionales eran conscientes de que una ley de estas características debía contar con un amplio respaldo si quería no sólo salir adelante, sino también perdurar en el tiempo... De hecho, la gran dificultad del proceso para aprobar la ley se ha reflejado en claramente en dos aspectos: en primer lugar, en lo referente a su contenido, que apuesta por un delicado equilibrio entre distintas opciones normativas, para intentar reflejar las aportaciones de todas las partes en beneficio del acuerdo; y en segundo lugar, en el complejo procedimiento seguido para la redacción definitiva de su contenido» ${ }^{39}$.

Me he referido en otro lugar ${ }^{40}$ al complejo procedimiento de «gestación» de la Ley, ¡cómo no, tratándose de una ley capital para el entramado institucional y territorial vasco! y lo he llegado a calificar como una especie de carrera de vallas, vallas que había que ir saltando, desactivando al mismo tiempo todo tipo de «minas» que surgían por doquier, que podían explotar en cualquier momento y por ende, dar al traste con la Ley, como desgraciadamente había sucedido con intentos anteriores para aprobar una Ley municipal vasca.

Sin embargo, el complejo proceso llegó a buen puerto y se consiguió aprobar la Ley en el Parlamento Vasco con una mayoría holgada, sin gran oposición por parte de las fuerzas políticas que no la apoyaron y que tuvieron la visión política y la generosidad — todo hay que decirlo— de no «torpedearla», contando con el decidido apoyo de la Asociación de Municipios Vascos (EUDEL), sin que los Territorios Históricos, siempre celosos vigilantes de su «estatus foral» y en aquel momento en manos de tres fuerzas políticas muy distintas y contrapuestas entre sí, se opusieran a ella como había ocurrido con proyectos anteriores y negociando también con el Gobierno Central para evitar posibles impugnaciones de éste ante el Tribunal Constitucional.

No hay espacio en este artículo, ni tampoco es objeto principal del mismo entrar en un examen pormenorizado ni de la LILE en general, ni de las competencias de las entidades locales recogidas en la Ley, que se encuentran desarrolladas en el Título III de la misma ${ }^{41}$. En dicho Título se definen los principios generales del sistema de competencias (art. 14), el mismo concepto de competencia de las entidades locales territoriales (art. 15), la cláusula universal de competencias que no tengan el carácter

39 Exposición de Motivos de la LILE, apartado I. Conviene también tener en cuenta su apartado III, en cuanto al procedimiento seguido.

40 LARRAZABAL BASAÑEZ, S. «Zumen hauekin... ekin lanari», op. cit., págs. 29-32.

41 Para ello, recomiendo especialmente el número monográfico que la Revista Vasca de Administración Pública ha dedicado a la LILE: Revista Vasca de Administración Pública, 107-II (enero-abril 2017) y que contiene valiosas aportaciones de distintos especialistas acerca de los contenidos más importantes de la Ley de Instituciones Locales de Euskadi. 
de competencias propias, transferidas o delegadas(art. 16), el listado de competencias propias de los municipios (art. 17), o lo relativoa las atribuciones, delegaciones y transferencia de competencias (arts. 18-23).

Y ya que hablamos de calidad democrática, un claro ejemplo de la apuesta de la LILE por profundizar en ella, lo constituyen las previsiones del Título VI de la misma, relativo al Gobierno abierto, transparencia, datos abiertos y participación ciudadana. Y una vez más, sorprende que el complejo modelo territorial vasco nos ofrece aquí otro ejemplo de cómo el hecho de que cada nivel institucional tenga sus propias normas de transparencia, asunto exigido por el respeto a las competencias de cada uno, hace que exista un saludable proceso de emulación entre instituciones para avanzar en el diseño de instrumentos que refuercen la transparencia ${ }^{42}$ y la participación ciudadana ${ }^{43}$.

Finalmente, por enunciar algún ejemplo más, sacado de la Ley de Instituciones Locales de Euskadi, de cómo la participación y la colaboración entre sí de las instituciones de los tres niveles institucionales vascos puede ayudar a profundizar en la

${ }^{42}$ Una vez más, también aquí se reproduce el esquema de organización territorial vasco: está previsto que las Instituciones Comunes de la Comunidad Autónoma cuenten en breve con una moderna legislación en la materia. Cuando escribo estas líneas, se encuentra en tramitación en el Parlamento Vasco laProposición de Ley de Transparencia y Participación ciudadana de la Comunidad Autónoma de Euskadi, presentada en el Parlamento Vasco en julio de 2017 y admitida a trámite por la Mesadel http:// www.legebiltzarra.eus/irud/11/00/005644.pdf; (última consulta, 13 de septiembre de 2017). Por su parte, cada uno de los tres Territorios Históricos tiene su propia normativa al respecto:Bizakaia, su Norma Foral1/2016, de 17 de febrero, de Transparencia de Bizkaia (Boletín Oficial de Bizkaia n. 37 , de 24 de febrero de 2016); Gipuzkoa, su Norma Foral 4/2014, de 6 de febrero, de transparencia y acceso a la información pública (Boletín Oficial de Gipuzkoa, n. ${ }^{\circ}$ 26, de 10 de febrero de 2014); y Álava, su Norma Foral 1/2017, de 8 de febrero, de transparencia, participación ciudadana y buen gobierno del sector público del Territorio Histórico de Álava (Boletín Oficial del Territorio Histórico de Álava, n. ${ }^{\circ} 21$, de 20de febrero de 2017). Por su parte, para el ámbito municipal vasco, la regulación se encuentra precisamente en el Título VI de la LILE a la que me acabo de referir.

43 Algo similar ocurre con la participación popular en la iniciativa de Leyes o Normas Forales, es decir, la iniciativa legislativa popular (ante el Parlamento Vasco) o la iniciativa normativa popular (ante alguna de las Juntas Generales de Bizkaia, Gipuzkoa o Álava), denominada así porque éstas no aprueban normas con rango formal de ley sino Normas Forales. En el ámbito de las Instituciones Centrales de la Comunidad Autónoma, se encuentra regulada en la Ley del Parlamento Vasco 10/2016, de 30 de junio, reguladora de la iniciativa legislativa popular (Boletín Oficial del País Vasco, n. ${ }^{\circ} 129$, de 7 de juliode 2016). En el ámbito de los tres Territorios Históricos, hay que destacar, en Bizkaia, desde su Norma Foral4/1985, de28 de junio, reguladora de la iniciativa normativa popular (Boletín Oficial del Señorío de Bizkaia, n. ${ }^{\circ}$ 169, de 24 de julio de 1985), hasta la Norma Foral 3/2017, de 12 de julio, por la que se regula el procedimiento de iniciativa normativa de los Ayuntamientos de Bizkaia ante las Juntas Generales del Territorio Histórico (Boletín Oficial de Bizkaia, n. ${ }^{\circ}$ 138, de19 de julio de 2017); en Gipuzkoa: la Norma Foral 7/2007, de 10 de abril, reguladora de la iniciativa normativa popular ante las Juntas Generales de Gipuzkoa (Boletín Oficial de Gipuzkoa, n. ${ }^{\circ}$ 79, de 29 de abril de 2007) y la Norma Foral 1/2010, de 8 de julio, sobre participación ciudadana (Boletín Oficial de Gipuzkoa, n. ${ }^{\circ}$ 132, de 14 de julio de 2010); en Álava: Norma Foral 15/1986, de 4 de julio, reguladora de la iniciativa normativa popular ante las Juntas Generales de Álava (Boletín Oficial del Territorio Histórico de Álava, n. ${ }^{\circ} 89$, de 6 de agosto). 
calidad democrática, es obligado citar al Consejo Vasco de Políticas Públicas Locales que, como dice el art. 84 de la Ley, es la estructura institucional de representación y participación de los Municipios en las Instituciones de la Comunidad Autónoma Vasca y que tiene por función garantizar el pleno respeto de la autonomía local por parte de dichas instituciones. En dicho Consejo están representados los tres niveles institucionales vascos de forma paritaria, siguiendo el modelo vasco, pues consta de dieciocho vocales: seis en representación del Gobierno Vasco, dos por cada una de las tres Diputaciones Forales y seis en representación de los municipios vascos (art. 85).

Éste es un modelo que podría generalizarse, por ejemplo a través de la creación de un Consejo Vasco de Políticas Públicas con configuraciones sectoriales según los asuntos a tratar, tal y como se dice en el propio Informe sobre Análisis y Funcionamiento de la Comunidad Autónoma de Euskadi antes citado, puesto que ello permitiría profundizar en la cooperación, dotando de mayor cohesión al conjunto de los poderes de los tres niveles institucionales que, en el ejercicio de sus competencias, actúan en el mismo territorio y sobre los mismos ciudadanos, para debatir asuntos de interés común, acordar entre todas las instituciones actuaciones que faciliten la resolución de problemas relativos a posibles invasiones de competencias de unas instituciones sobre otras (intentando prevenir esos problemas a través de la creación de mecanismos de alerta temprana, elaborando propuestas normativas que las eviten, etc.), lo que permitiría también incrementar la interacción, colaboración y coherencia entre los tres niveles institucionales vascos, incluida la evaluación de políticas públicas. Todo ello redundaría en una mayor cohesión y eficacia de las mismas y, en definitiva, en un mejor servicio a los ciudadanos, para potenciar la calidad democrática, que es el objetivo que se pretende conseguir ${ }^{44}$.

\section{CONCLUSIÓN}

En definitiva, tal como parecen demostrar algunos de los datos concretos que ofrezco en este apartado, la tesis que he intentado defender en este trabajo es que además de otros factores muy relevantes, como por ejemplo, su particular sistema de financiación a través del sistema de Concierto Económico, el funcionamiento del actual modelo institucional y territorial vasco, a pesar de su complejidad, con sus luces y sombras, podría ser un ejemplo más que confirmase la idea ampliamente extendida de que un modelo de organización territorial descentralizado y sus complejas, pero al mismo tiempo valiosas formas de interacción entre los diversos niveles de gobierno, pueden potenciar la calidad del gobierno de sus instituciones ${ }^{45}$, ayudar en el desarrollo

44 «Informe sobre el análisis y funcionamiento institucional en la Comunidad Autónoma de Euskadi», op. cit., págs. 70-77.

${ }^{45}$ CHARRON, N. / LAPUENTE, V. et al. (2010), Measuring the quality of government and subnational variation. Report for the European Commission. Directorate General Regional Policy. Directorate Policy Development, Universtity of Gothenburg, December 2010. Parte I-a, pág. 54:http://ec.europa.eu/ 
económico ${ }^{46}$, humano y social del País ${ }^{47}$, fomentar la protección social ${ }^{48}$, aumentar la transparencia ${ }^{49}$, ayudar a gestionar mejor $\operatorname{los}_{\text {servicios }}{ }^{50} \mathrm{y}$, en definitiva, mejorar la calidad democrática de la sociedad..$^{51}$

regional_policy/sources/docgener/studies/pdf/2010_government_1.pdf (última consulta, 10 de septiembre de 2017). En lo que se refiere al País Vasco, puede consultarse la Parte IV. (Case Study Reports. País Vasco, —ES 21-, a cargo de HERNÁNDEZ RAMÍREZ, M., págs. 110-125): http://www.qog.pol.gu.se/ digitalAssets/1358/1358343_final-report---part-4.pdf (última consulta, 10 de septiembre de 2017). De estos mismos autores puede consultarse también: CHARRON, N. / LAPUENTE, V. (2018), Quality of Government in EU Regions. Spatial and temporal patterns, University of Gothenburg: The Quality of Goverment Institute (QOG), Working Paper Series, 2018-1, pp. 20, 22, 33.

https://gupea.ub.gu.se/handle/2077/55591?locale=en (última consulta 5 de noviembre de 2018)

46 Para consultar algunos datos sobre el desarrollo económico de la Comunidad Autónoma Vasca en comparación con otras Comunidades Autónomas y con el Estado, puede verse, por ejemplo: https:// www.datosmacro.com/ccaa/comparar/pais-vasco/espana (última consulta, 19 de febrero de 2018).

47 A este respecto, son significativos los datos relativos al Índice de Desarrollo Humano - IDHrelativos a la Comunidad Autónoma Vasca (que obtiene una puntuación de 0,915 sobre 1, según los cálculos del Instituto Vasco de Estadística —EUSTAT_- aplicando la metodología del Programa de las Naciones Unidas para el Desarrollo — PNUD— para el período 2010-2014 —últimos datos disponibles—). Como es sabido, el IDH mide el desarrollo de un país en función de tres dimensiones: salud (esperanza de vida), educación (años de escolaridad) y nivel económico (ingresos por cápita) y estos datos sitúan a Euskadien los primeros puestos de la clasificación correspondiente a este índice. A este respecto, pueden consultarse:

http://www.eustat.eus/elementos/ele0013500/Indice_de_Desarrollo_Humano_de_la_CA_de_Euskadi_por_dimensiones_indicadores_e_indices/tbl0013567_c.html

http://www.eustat.eus/indicadores/ambito_99/temaseleccionado_48/indicadoresEstruc.html http://www.eustat.eus/estadisticas/tema_404/opt_0/tipo_1/ti_Indice_Desarrollo_Humano/temas.html (última consulta, 6 de noviembre de 2017).

${ }_{48}$ Sobre el fomento de la protección social, y en relación con los gastos realizados por las Administraciones Vascas pertenecientes a los tres niveles institucionales vascos: Lanbide (Gobierno Vasco), Diputaciones Forales y Ayuntamientos, que conforman el Sistema Vasco de Servicios sociales puede consultarse:

http://es.eustat.eus/elem/ele0014400/not0014487_c.pdf(última consulta, 19 de febrero de 2018).

49 De hecho, y según los últimos datos que aparecen en los Índices de Transparencia elaborados por Transparencia Internacional España (última consulta, 10 de septiembre de 2017):

la Comunidad Autónoma Vasca obtiene 100 puntos sobre 100 en el Índice de Transparencia de las Comunidades AutónomasINCAU-2016, y es la Comunidad Autónoma más transparente de España:

http://transparencia.org.es/wp-content/uploads/2016/12/resultados_2016_aspectos_destacados.pdf;

Asimismo, algunos de sus municipios más importantes (Bilbao, Vitoria-Gasteiz, Barakaldo), han obtenido la máxima puntación en transparencia, es decir 100 puntos sobre 100- según el Índice de Transparencia de los Ayuntamientos ITA-2017:

http://transparencia.org.es/wp-content/uploads/2017/07/aspectos_destacados_ita_2017.pdf.

En cuanto a los Territorios Históricos vascos, la Diputación Foral de Bizkaia, obtuvo también 100 puntos sobre 100 en el Índice de transparencia de las Diputaciones (INDIP):

http://transparencia.org.es/wp-content/uploads/2015/12/objetivos_indip_2015.pdf

${ }^{50} \mathrm{http}: / /$ www.elmundo.es/pais-vasco/2016/01/22/56a1eac646163f3b328b45e6.html (última consulta, 11 de septiembre de 2017).

${ }^{51}$ ORKESTRA (Instituto Vasco de Competitividad - Fundación Deusto), Informe de Competitividad del País Vasco 2017 ¿y mañana? (2017), Donostia-San Sebastián, Publicaciones de la Universidad de Deusto, págs. 189-202. Esta publicación puede consultarse «on line» en: http://www.orkestra.deusto.es/images/ investigacion/publicaciones/informes/2017-orkestra-informe-competitividad.pdf? $v=01$. (última consulta, 10 de septiembre de 2017).

N.o 103, septiembre-diciembre 2018, págs 303-330 


\section{Title}

Democratic quality, institutional system and Basque territorial model

\section{Summary}

1. Introduction. 2. The distribution of competences between the Common Institutions of the Autonomous Community of Euskadi and the Regional Administrative Bodies of the Historical Territories ofBizkaia, Gipuzkoa and Álava. 2.1. The distribution of competences in the Statute of Autonomy of the Basque Country. 2.2. The distribution of competences in the Law of Historical Territories. 3. The competences of the municipal institutions of Euskadi. 4. Conclusion.

\section{Resumen}

La tesis que se defiende en este trabajo es que el complejo modelo institucional y territorial vasco funciona aceptablemente bien, a pesar de sus luces y sombras, y puede ser un ejemplo de la idea ampliamente generalizada de cómo un modelo de organización territorial descentralizada (y sus complejas, pero al mismo tiempo, valiosas formas de interacción entre los distintos niveles de gobierno), pueden mejorar la calidad del gobierno de sus instituciones, ayudar en el desarrollo humano, económico y social, aumentar la transparencia, administrar los recursos disponibles para ofrecer mejores servicios públicos y, en definitiva, mejorar la calidad democrática de la sociedad.

\section{Abstract}

The thesis defended in this paper is that the complex Basque institutional and territorial model works acceptably well, despite its lights and shadows, and can be an example of the widespread idea of how a model of decentralized territorial organization (and their complex, but at the same time valuable forms of interaction between the various levels of government), can enhance the quality of government of their institutions, help in the human, economic and social development, raise transparency and manage available resources to deliver better public services and, in short, improve the democratic quality of society.

\section{Palabras clave}

Calidad democrática. Sistema institucional vasco. Modelo territorial vasco.

\section{Keywords}

Democratic quality. Basque institutional system. Basque territorial model. 